\title{
Task 57
}

Solar Standards and Certification

\section{Position Paper on}

\section{Solar Standards and Certification}

March 2019 


\section{Contents}

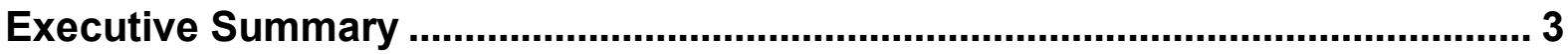

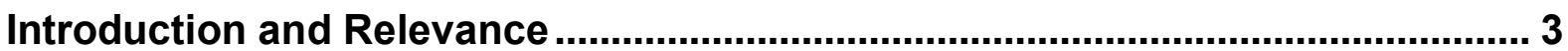

Status of Solar Thermal Standards and Certification .......................................... 4

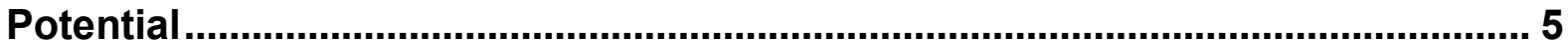

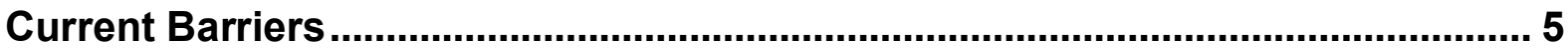

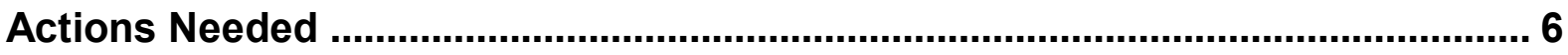

Annex: List of ISO Standards for Solar Thermal Systems and Components ..... 7

This document was prepared by Jan Erik Nielsen of SolarKey International, Denmark and Operating Agent for SHC Task 57: Solar Standards and Certification.

(c) IEA Solar Heating and Cooling Technology Collaboration Programme, www.iea-shc.org The IEA SHC Technology Collaboration Programme (SHC TCP) is organized under the auspices of the International Energy Agency (IEA) but is functionally and legally autonomous. Views, findings and publications of the SHC TCP do not necessarily represent the views or policies of the IEA Secretariat or its individual member countries." 


\section{Solar Standards and Certification - Position Paper}

The purpose of this paper is to illustrate the relevance and importance of standardization and certification in the field of solar thermal products - and to show the benefits of harmonizing standardization and certification at the international level.

The benefits are clear:

- Increases product quality.

- Saves very significant resources for product testing and certification.

To obtain these benefits, it is necessary to:

- Allocate resources for standardization development/maintenance.

- Have international cooperation on certification - including harmonization of national product requirements.

- Promote use of international standards.

\section{Executive Summary}

Harmonizing - at the international level - testing standards and certification schemes could:

- Save significant resources for product testing and certification.

- Increase product quality.

This will create less expensive and improved solar thermal products thus leading to bigger markets, and potentially starting a good circle towards a breakthrough for solar thermal all over the world!

Some well recognized international standards (ISO Standards) for testing of solar thermal systems and components are available. The tasks/challenges are:

- Continuous updating and adapting to new technology, products and requirements.

- Promoting the use of the standards

Quite a few well-established national/regional certification schemes exist around the world. The tasks/challenges are:

- Harmonizing these existing certification schemes.

- Establishing new certification schemes where needed.

\section{Introduction and Relevance}

There is a huge potential for saving resources for testing, inspection and certification if the same or similar standards and certification procedures are used by all countries.

To illustrate this point, two scenarios are given below. 


\section{Scenario I: National standardization and certification}

Each country has its own standards and certification scheme. To enter the market in a country a manufacturer must have his products tested according to the national standards and certified by a national certification body. If a manufacturer sells 3 solar products in 7 countries, he will need 21 tests and certificates - including regular inspection of his production line(s) by inspectors from 7 countries.

\section{Scenario II: International standards and harmonized certification}

All countries implement the international standards as national standards and establish harmonized certification schemes. To enter the markets everywhere, a manufacturer only needs a product tested and certified once. If a manufacturer sells 3 solar products in 7 countries, he will need $\mathbf{3}$ tests and certificates - including regular inspection of his production line(s) by 1 inspector.

\section{Savings in testing and inspections from Scenario I to Scenario II}

As shown in these scenarios, a manufacturer can reduce testing and inspections by a factor of 7 by using international standards and harmonized certification schemes.

\section{Status of Solar Thermal Standards and Certification}

\section{Status on standards}

There are several international standards (ISO Standards) for solar thermal products that cover a wide range of solar systems and components (see Annex).

The ISO committee TC 180 has developed and is maintaining these standards. ISO/TC180 is currently functioning reasonably well but needs participation from more countries and more active participation in general.

At this time, there are important product types on the market not covered and some standards urgently need updating.

Work that is ongoing or has been initiated addresses:

- insulation materials in collectors

- compact solar water heaters

- building integration of solar collectors/systems

- accelerated aging test of collectors

- performance check of large field of solar collectors

New hybrid technologies, such as $\mathrm{PVT}^{1}$ collectors and systems as well as "PV" heating systems" and "HP ${ }^{3}$ / solar systems" are entering the market. This creates a need to develop standards for these products. Products not covered by standards will experience problems entering markets that require certified products ${ }^{4}$. Furthermore, there are requests from different actors to simplify the testing standards ${ }^{5}$.

\footnotetext{
${ }^{1}$ PVT: Photovoltaic and Thermal

2 PV: Photovoltaic

${ }^{3} \mathrm{HP}:$ Heat Pump

4 To certify a product, you need a standard to state compliance with

${ }^{5}$ Such work could be initiated by elaborating the ToR (Terms of Reference) for "Simpler Test Standards."
} 


\section{Status on certification}

There are several national certification schemes around the world and so far, two regional (multi-national) certification schemes.

A good example of a regional certification scheme is the pan-European certification scheme Solar Keymark ${ }^{6}$. This scheme covers all of Europe, so the entire European market is open to products with the Solar Keymark certification.

The other regional certification scheme is $\mathrm{SHAMCI}$ for the North African and Arab region. It is inspired by the Solar Keymark and has just recently come into operation.

Countries without well-functioning certification schemes could have issues with product quality thus negatively impacting the market.

A global initiative is the Global Solar Certification Network (GSCN), a network of certification bodies, inspectors, test labs and solar thermal industries. The GSCN facilitates cooperation between solar certification bodies/schemes around the world. When a product has been certified by one of the participating certification bodies/schemes, the product can obtain certification from other participating certification schemes without re-testing of the product and without re-inspection of production facilities.

So far, the GSCN concept works for solar collectors - the next step is to add compact solar water heaters.

\section{Potential}

Harmonizing - at the international level - testing standards and certification schemes could:

- Save significant resources for product testing and certification.

- Increase product quality.

This will again lead to less expensive and improved solar thermal products leading to bigger markets - and potentially start a good circle towards a breakthrough for solar thermal all over the world!

\section{Current Barriers}

The barriers for developing and maintaining ISO standards are:

- Lack of quality infrastructure in general in some countries.

- Lack of resources to participate in national standardization work groups.

- Lack of resources to participate in international standardization work.

- Lack of persons willing to take responsibility for convening international standardization work.

- Lack of industry participation in standardization work.

- Lack of interest in harmonizing standards and certification (protection of domestic industry).

\footnotetext{
${ }^{6}$ Solar Keymark is part of the CEN Keymark certification system
} 
- Countries not participating for one or the other reason.

- Country specific requirements for test procedures due to local specific conditions (not considered in the international standard).

The barriers for harmonizing certification schemes are:

- Lack of industry participation and support - manufacturers operating in several national markets have a clear interest, but manufacturers operating only in their home market may not see the benefits.

- Lack of interest in harmonizing certification schemes (protection of national certification bodies).

- Country specific requirements in certification schemes due to local specific conditions.

\section{Actions Needed}

Actions are needed from the key actors.

- Industry:

- Organize at multinational/global level.

- Participate in ISO standardization and in developing/updating standards.

- Participate in the Global Solar Certification Network.

- Put pressure on test labs and certification bodies to use harmonized standards and certification schemes.

- Put pressure on national authorities to harmonize requirements.

- National authorities:

- Harmonize requirements (as far as possible) at the international level.

- Adopt international standards.

- Support international standardization work and development/updating of standards.

- Test labs:

- Use the international standards.

- Participate in ISO standardization and in developing/updating standards.

- Participate in the Global Solar Certification Network.

- Put pressure on national authorities to harmonize requirements.

- Certification bodies:

- Accept the international standards.

- Actively work towards the international harmonization of certification schemes.

- Participate in the Global Solar Certification Network.

- Put pressure on national authorities to harmonize requirements.

- International funders:

- Support international standardization work and the development/updating of standards.

- Support establishing a standardization and certification infrastructure in emerging markets. 


\section{Annex: List of ISO Standards for Solar Thermal Systems and Components}

\section{Published standards}

- ISO 9553:1997 Solar energy - Methods of testing preformed rubber seals and sealing compounds used in collectors

- ISO 9806:2017 Solar energy - Solar thermal collectors -Test methods

- ISO 9808:1990 Solar water heaters - Elastomeric materials for absorbers, connecting pipes and fittings - Method of assessment

- ISO 22975-1:2016 Solar energy - Collector components and materials, Part 1: Evacuated tubes -- Durability and performance

- ISO 22975-2:2016 Solar energy - Collector components and materials, Part 2: Heatpipes for solar thermal application - Durability and performance

- ISO 22975-3:2014 Solar energy - Collector components and materials, Part 3: Absorber surface durability

- ISO/FDIS 22975-5 [Under development] Solar energy - Collector components and materials -- Part 5: Insulation material durability and performance

- ISO 9459-1:1993 Solar heating - Domestic water heating systems, Part 1: Performance rating procedure using indoor test methods

- ISO 9459-2:1995 Solar heating - Domestic water heating systems, Part 2: Outdoor test methods for system performance characterization and yearly performance prediction of solar-only systems

- ISO 9459-4:2013 Solar heating - Domestic water heating systems, Part 4: System performance characterization by means of component tests and computer simulation

- ISO 9459-5:2007 Solar heating - Domestic water heating systems, Part 5: System performance characterization by means of whole-system tests and computer simulation

\section{Standards under development}

- $\quad$ ISO/NP 9488 Solar energy - Vocabulary

- ISO/FDIS 22975-5 Solar energy - Collector components and materials, Part 5: Insulation material durability and performance 